\title{
XXXVII. On the fracture of electrical jars by spontaneous discharges
}

\author{
Mr. Thomas Howldy
}

To cite this article: Mr. Thomas Howldy (1815) XXXVII. On the fracture of electrical jars by spontaneous discharges, Philosophical Magazine Series 1, 46:209, 205-208, DOI: $10.1080 / 14786441508638523$

To link to this article: http://dx.doi.org/10.1080/14786441508638523

里 Published online: 27 Jul 2009.

Submit your article to this journal $₫$

Џ Article views: 2

Q View related articles $\square$ 


\section{[ 205 ]}

XXXVII. On the Fracture of Electrical Jars by spontaneods Discharges. By $M r$. Thiomas Howldy.

\section{To Mr. Tillock.}

SiR, $-T_{\text {HE perforation or fracture of Leyden jars, which some- }}$ times takes place when they explode spontaneously, and at other times when they are intentionally discharged, is a phænomenon which has often obtruded itself upon the notice of electricians; and yet, so far as I can learn, its cause has not been investigated with much eare. My attention was forcibly attracted to this subject a few years since, by the following circumstance:-A small electrical battery of nine jars, that had been charged pretty high, exploded spontaneously at the moment when I was going to discharge it. On examining the jars after the explosion, it was found that three of them had been perforated nearly in the middle between the top and bottom of the coating. The jars of this battery were four inches in diameter and twelve high, having uncoated margins two inches broad. As I was not then aware that similar accidents had occurred to other experimenters, and as I had never before had more than one jar broken by any single explosion of the battery, $I$ was greatly surprised at the fracture of three on this occasion, and could not account for it in any manner satisfactory to myself. The most plausible conjecture that I was able to form concerning its cause was, that the communication between the charging wires and the inside, coatings of the jars was not sufficiently extensive; so that, when the discharge of the battery was inade, the whole charge of each jar, rapidly converging to the single and very limited point of contact between its coating and the charging wire, experienced a proportionate condensation and resistance on entering it, which caused a momentary retardation of its velocity, and consequently a momentary reaction of the charge from that point against the sides of the jars; which reaction, when the charge had considerable intensity, might be sufficient to burst one or more of them.

I determined, therefore, to make some experiments with the least injured of the fractured jars, in order to ascertain t!se probability or improbability of this conjecture. With this intention I removed the damaged jars from the battery; and findin: that one of them was simply perforated without having any lateral cracks extending from the hole, I took from round it nearly an inch in breadth both of the exterior and interior coating, and made each side of the glass perfectly clean. The jar was then placed directly below the ball and wire at the extremity of the 
prime conductor of the electrical machine, one end of a chain being annexed to the wire, while the other end of it descended into the jar and came in contact with the middle of its bottom, so that the suspended part of the chain was at equal distinces from the opposite sides of the jar. The chain was thus connected with the bottom only of the inside coating, in order that the jar might be charged and discharged as nearly as possible under the same circumstances as when it was in the battery; the jars of which have their charging wires in communication with the interior coating at the bottom of each, and nowhere else. The jar being disposed as described above, the object of the first experiment was to ascertain how many turns of the wheel were necessary to make it explode spontaneously through the perforation in its sirle.

Exp. 1.-The wheel being turned, on completing its eighth revolution an explo ion took place through the perforation in the jar. The charge with which the jar exploded through the perforation being thus known, I now wished to communicate to it the greatest charge it would bear without so exploding; in order that the jar might be discharged in the usual way, and that I might observe at the moment of its discharge whether any appearance worthy of notice would occur at the perforation.

Exp. 2.-The jar was next charged by something more than seven turns of the wheel; one ball of an insulated discharging rod was then put in contact with its exterior coating at the same height as the perforation, and at ahout three inches distance from it : on making the other ball of the rod approach the ball communicating with the inside of the jar, a vivid spark was seen to pass between the two balls, and at the same moment a similar spark with respect to brilliancy and strength was likewise seen to pass between the interior and exterior coatings of the jar through the perforation in its side. Although the result of this experiment scemed to confirm my conjecture as to the cause of the bursting of the jars before related, yet it occurred to me that possibly the spark through the perforation might have been occasioned by the mode in which the jar had been discharged : to ascertain this, the jar was repeatedly charged as in Exp. 2, and was afterwards discharged by putting one ball of the discharging rod in contact at different times with different parts of its exterior coating, more or less distant from the perforation; and by bringing the other ball either more slowly or more quickly towards the ball communicating with the inside of the jar; but in all these instances the same phænomena occurred. Two sparks were always seen to pass simultaneously; one between the two balls, and the other between the 
two coatings of the jar through the perforation in its side. Being now satisfied that the latter spark did not depend on the mode in which the discharge was effected, I proceeded to conncet the upper part of the inside coating of the jar in six different points with the chain, by means of three pieces of metallic wire placed in the jar diameterwise, their opposite ends pressing somewhat stiffly against its opposite sides. The jar was then charged and discharged twice, as before; and at each discharge the spark again occurred at the perforation without any sensible difference in its appearance: but on attempting to repeat the experiment the thir time, the charge exploded before it had arrived at its former intensity; and on examining the perforation there were now found several fractures proceeding from it, through one or other of which the jar, during every succeeding attempt to charge it, continued to explode; notwithstanding several expcdients were employed to prevent it. The jar having thus become unable to retain a charge sufficient for the purpose in view, and the other damaged ones appearing to be so fractured as to forbid any attempt to employ them, I was unable to proceed further in the inquiry, and obliged to rest satisfied with having ascertained the following facts :

1. That when a Leyden jar, under the circumstances already described, is charged to a certain height, and then discharged in the usual way, - the charge will separate or divide itself into two portions, one of which will pass through the metallic medium employed to produce the discharge; while the other portion will pass from one coating of the jar to the other, through the perforation in its side.

2. That this separation of the charge takes place with every mode of discharge by which a spark is elicited at the ball of the charging wire.

3. That when the charging wire communicates in several points with the upper part of the eoating, all other circunstances remaining the same, the separation of the charge still ensues; and the ratio of its separated portions to each other experiences no sensible alteration.

Should future experiments show that this phænomenon depends on the limited and imperfect communication with the inside of the jar, it would afford information of much practical usefulness. If, on the contrary, it should be found to be wholly independent of that circumstance, the investigation of its cause would still be interesting, as its discovery would perhaps throw additional light upon the other singular phænomena of the Leyden jar. These considerations, together with the uncertainty whether I may hereafter have the opportunity and means of resuming and completing the inquiry, have induced me to lay it before 
before your readers in its present imperfect state, and to take the liberty of suggesting the following hints for its further prosecution.-Three jars of equal electrical capacity with one another might be taken,and a hole full a quarter of an inch in diameter be drilled in each. One of them should have the hole near the top of its coating; the second in its middle; and the third near its bottom. The holes being of this size and the glass tolerably thick, the explosions would pass through them from coating to coating without injury to the jars. If, however, stronger charges should be required than might with safety to the jars be employed in this manner, the coating round the holes might be removed to a greater distance, and two wires having a small ball on one extremity of each might be connected with the opposite coatings of the jars; the opposing balls being placed at a small distance from each other and opposite the centre of the holes: the explosions might then be made to pass through them from ball to ball without acting on the glass, and the experiments might be repeated as often as necessary without fear of damaging the jars. Cuthbertson's balance electrometer would likewise be useful for regulating with accuracy the strength of the charges. - A series of experiments made with each jar separately, and another series with the jars combined, under every variety of circumstance which might influence the results, would, it is probable, add something more to our knowledge of the laws which regulate the action of the electric fluid.

Should any of your ingenious and able correspondents be induced by this communication to investigate the subject of it, I shall have obtained by making it the only object I had in view. I am, sir,
Hereford, Sept 14, 1815.

XXXVIII. New Ontlines of Chemical Philosophy. By Ez. Wasken, Esq. of Lynn, Norfolk.

[Comilived from vol, xlv, p. 432,]

$\mathrm{T}$

HE phancmena of electricity are investigated in a much more satisfactory nimuer by low degrees of excitement, than by more powerful artificial means. For when very large electrical maclines are used, all the air contained in a room soon becomes electrificd, which puts a total stop to all investigations upon its natural properties; nay, even a single candle burning in a room soon alters the state of the air which it contains*.

* "The repellency between the cork-ball and the shot (the prime conductor which the Doctor made use of ) is destroyed by candle-light, even though the candle be at a foot distance."-Franklin's Works, vol, i. p. 172.

The 